\title{
Practice and Exploration of Online Course Construction for Methods of Mathematical Physics
}

\author{
Dong Xue ${ }^{1, a^{*}}$, Xingfang Zhang ${ }^{2, b}$ and Bin Zhang ${ }^{c}$ \\ ${ }^{1}$ School of Opto-Electronic Engineering, Zaozhuang University, Zaozhuang 277160, China \\ ${ }^{2}$ Zaozhuang Engineering Research Center of Terahertz, Zaozhuang 277160, China \\ afiberlaser@126.com, bxf4114@126.com, 346658317@qq.com
}

Keywords: Online course; Course construction; Flipped classroom; E-learning; Education reform

\begin{abstract}
Although the traditional lecture prevails in higher education as the most popular teaching method, recent technological advances have made possible blended or hybrid learning classrooms, in which students learn at least in part through online delivery of content. Online course construction is one of the quality projects from Education Department, which is of great significance for the improvement of teaching quality in university and achievement of talent developing objectives. Facing the reality of popularization in higher education, and combining with the opportunity of online course construction in our university, the online teaching system for Methods of Mathematical Physics (Complex Variables Functions and Integral Transform) is designed with Chaoxing Online Platform. The teaching effect between online flipped classroom and traditional lecture based classroom is also compared with statistical analysis. The results show that the flipped classroom has great advantages both in the scores of final exam and the evaluation of course teaching.
\end{abstract}

\section{Introduction}

Recent reform of education highlights the growing concerns about the capability of the current educational model to equip students with essential skills for future career development [1-4]. As for the methods of mathematical physics, although many attempts have been made to address the problem of the decreasing teaching time and the increasing load of practice content, a growing body of literature indicates the need to reform the current teaching strategies.

Massive Open Online Courses (MOOCs) came to prominence in 2012 and have been sweeping the world's higher education in recent years for the teaching and learning of different subjects [5-8]. MOOCs have been successfully attracting tens of thousands of students all over the world by providing a variety of learning resources and opportunities. It pays more attention to the integration of excellent teaching resources and sets a revolutionary educational model for educators in such digital information age. However, MOOCs typically have low completion rates, at least when compared with traditional courses. Completion rates can be as much as $40 \%$, but less than $10 \%$ is typical [9-11]. Small private online courses (SPOCs) is a viable option, which support blended learning and flipped classroom learning. In this paper, an online teaching system is set up with Chaoxing Online Teaching Platform(COTP) based on the SPOCs model.

\section{Exploration of Online Course Construction for Methods of Mathematical Physics}

Facing the reality of popularization in higher education, and combining with the opportunity of online course construction in our university, the online teaching system for Methods of Mathematical Physics (Complex Variables Functions and Integral Transform) is designed with Chaoxing Online Platform. The online course url is as follows: https://mooc1-1.chaoxing.com/course/101807286.html.

The course under study is an upper-level undergraduate one-semester course that covers two separated parts: I Complex Variable Function and Integral Transform, II Mathematical Equations and Special Functions. The course is required for undergraduate majors of physics, electric information science and engineering, and opt-electric information science and engineering in our school. 
In order to strengthen the process assessment, our course is made up with variety of activates both online and offline. The diversity of the marking scheme is listed in Table 1 . All the videos of 48 hours lecture coupled with relative classroom test are upload online. Homework based on the COTP system provided an out-of-class opportunity for students to practice problem solving. Interactive discussing materials provided students with background readings, interactive illustrations, and assignable example problems of greater complexity than the online homework.

The course exams in this study were all constructed identically, contained assessment questions that probed very similar aspects of course content, and were presented at the end of each chapter. Each exam contained five questions, each one was worth 20 points. Every question was structured with several sub questions that, in general, increased in difficulty in progression through the question. Early sub questions typically involved straight forward applications, whereas late sub questions typically involved integration of concepts not explicitly covered in class. Nearly all questions involved mathematical calculations.

The final examination papers of the last few years, along with the answer keys are also provided to students to let them know the standardization of exam format and emphasis of content. We employ the course exams as a measure of student learning outcomes. The final exam does not play a significant role any more with this process-oriented marking scheme. Student must pay more attention to the assessment items at ordinary times.

Table 1 Marking Scheme

\begin{tabular}{cccccccccc}
\hline Items & Reading & Video & Test & Visits & $\begin{array}{c}\text { Discussio } \\
\mathrm{n}\end{array}$ & $\begin{array}{c}\text { Assignmen } \\
\mathrm{t}\end{array}$ & Interaction & Lecture & Exam \\
\hline Weight & $10 \%$ & $10 \%$ & $10 \%$ & $10 \%$ & $10 \%$ & $10 \%$ & $10 \%$ & $10 \%$ & $20 \%$ \\
\hline
\end{tabular}

\section{Practice of Flipped Classroom for Methods of Mathematical Physics}

Flipped classroom is a new pedagogical model in which students develop a basic understanding of the course materials before class, and use in-class for learner-centered activities, such as group discussion and presentation [12-16]. In this part, we assess the teaching effect of flipped classroom for course of methods of mathematical physics education, specifically complex variables functions teaching.

The participants selected were 90 students of two natural classes in School of Opto-Electronic Engineering. One class took the flipped classroom, while the other group took the traditional lecture based classroom. In the traditional classroom, students attended the didactic lecture and did the homework after class. In the flipped classroom, students were asked to watch the prerecorded lectures before the class, and use some of the class time for homework discussion. Both the teachers and students were asked to complete feedback questionnaires after the classroom. The data of comparison is listed in Table 2. The students are from two natural class of different undergraduate majors, just because there's only one class in the same major. So the class hour is not the same according to the syllabus of personnel cultivating program. The class hour of flipped group is only 32 , because that in the process of higher education and curriculum reformation across the country, in order to meet the need for training of applied talents, some new courses are added into the cultivating program, while some old courses like this one must be reduce in teaching hours. That's another reason we are forced to take flipped classroom mode to borrow some hours outside of the class.

Table 2 Comparison data of flipped and standard class

\begin{tabular}{ccc}
\hline Items & Flipped & Standard \\
\hline major of students & $\begin{array}{c}\text { electric information science and } \\
\text { engineering }\end{array}$ & $\begin{array}{c}\text { Opt-electric information } \\
\text { science and engineering }\end{array}$ \\
class size & 54 & 36 \\
class hour & 32 & 40 \\
minimum score & 45 & 50 \\
maximum score & 94 & 98 \\
average score & 79.5 & 68.6 \\
\hline
\end{tabular}


We found that the group from flipped classroom shows great advantages both in the scores of final exam and the evaluation of course teaching. The comparison of final examine score is shown in Fig. 1. The score of student from flipped classroom is much better according the statistical analysis. The population demographic data were analyzed using Chi-square test or independent samples t test. The scores of final exam were compared using independent samples t test. The questionnaire data were analyzed using Mann-Whitney-Wilcoxon test. All statistical analyses were performed in the SPSS software. $\mathrm{P}<0.05$ was considered statistically significant. Statistical show that there were no statistical differences between gender, age, and origin of student. While the final exam score showed that there were statistical differences between the two groups $(\mathrm{t}=3.49, \mathrm{P}=0.0008)$.

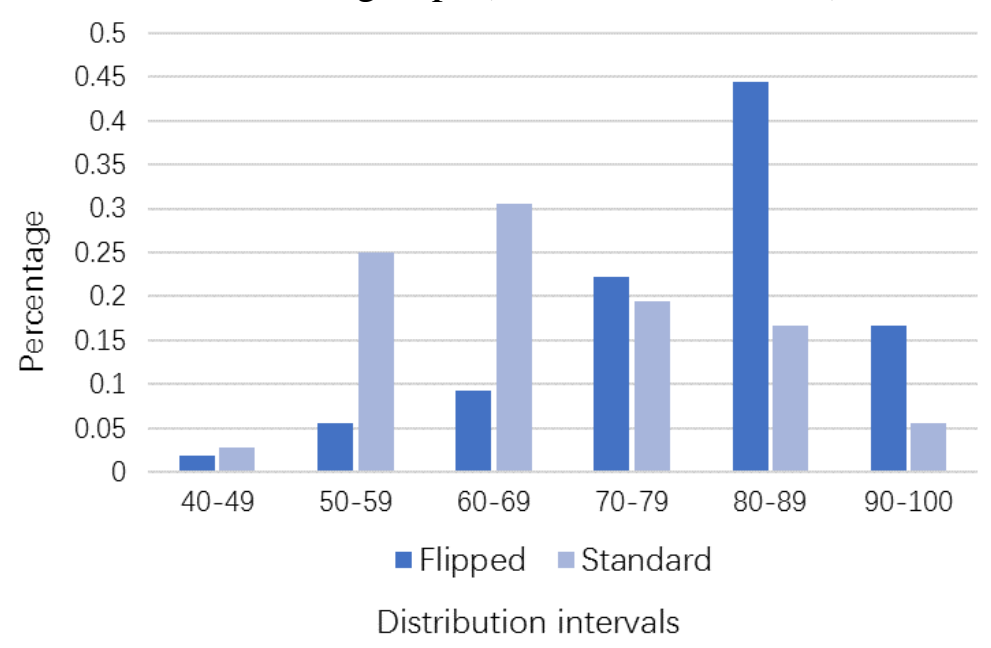

Figure 1. Exam scores of flipped course are significantly better than standard ones.

Moreover, the flipped classroom helped students to develop skills in problem solving, creative thinking and team working. Also, compared to the lecture-based classroom, both teachers and students were more satisfied with the flipped classroom. Therefore, the flipped classroom model for the methods of mathematical physics teaching showed promise as an effective teaching approach.

All students and teachers completed the questionnaires at the end of the session, students felt that the flipped classroom was more helpful in terms of developing team work and problem-solving skills. While more students in the traditional classroom tended to agree that the class was overly theoretical and abstract, the class work load was too heavy, and they did not have a clear idea of the expectation of the course. And the questionnaires also feedback that most of teachers thought that the flipped classroom met their expectations and the flipped classroom model was a more enjoyable and challenging way of teaching.

\section{Summary}

Based on flipped classroom strategies, an online teaching system is constructed for Methods of Mathematical Physics (Complex Variables Functions and Integral Transform) with Chaoxing Online Platform. Good results are obtained with this curriculum revolution. The experience is worth promoting to other courses.

\section{Acknowledgements}

This work is supported by national natural science fund project (No. 11447200); Shandong provincial natural science foundation (No.ZR201702200400); Science and technology program of Shandong higher education institutions (No. J17KA087); The program of independent innovation and achievement transformation plan for Zaozhuang (No. 2016GH19); Science and technology program of Zaozhuang (No. 2016GX31); The educational reform key projects of Zaozhuang University. 


\section{References}

[1] J.Y.Xiao, W.Dong: International conference on MEICI (Shenyang, China, September 24-26, (2016), P930.

[2] L.R.Halverson, C.R.Graham, K.J.Spring, J.S.Drysdale, C.R.Henrie: Internet High Educ, Vol.20, (2014), P20.

[3] C.H.Qin, Li.L: China University Teaching, (2015)No.12, P57 (In Chinese).

[4] D.C.Haak, J.H.Lambers, E.Pitre, S.Freeman:Science, Vol (2011),P1213.

[5] M. Cho, D. Shen: Distance Education, Vol.34 (2013), P290.

[6] S.Freeman, S.L.Eddy, M.McDonough, M.K.Smith, N.Okoroafor, H.Jordt, M.P.Wenderoth: Proc Natl Acad Sci USA, Vol.111 (2014), P8410.

[7] L. M.Black: Handbook of Distance Education (3rd ed.). (Routledge Publications, America 2013).

[8] A. R.Artino, K. D.Jones: The Internet and Higher Education, Vol.15 (2012) No.3, P170.

[9] Z.Zhan, H. Mei: Computers and Education, Vol.69 (2013), P131.

[10] B. J.Fishmann, R. W.Marx, S.Best, R. T.Tal: Teaching and Teacher Education (2003), P643.

[11] S.Buczynski, C. B.Hansen: Teaching and Teacher Education (2010), P599.

[12] H.Dack, C.A. Tomlinson: Educational Leadership( 2015), P10.

[13] M.Estrada, A.Woodcock, P.R.Hernandez, P.Schultz: J Educ Psychol ,Vol. 103 (2011). P206.

[14] S. H.Shaha, H.Ellsworth,. Journal Of Instructional Psychology, Vol.40 (2013) No1, P19.

[15] S. Y.Chyung, A. J. Moll, S. A.Berg: The Journal of EffectiveTeaching, Vol.10 (2010)No.1, P22.

[16]C. H.Wang, D. M.Shannon, M. E.Ross: Distance Education (2013), P302. 